\title{
Review
}

\section{Identification of estrogen-responsive genes based on the DNA binding properties of estrogen receptors using high-throughput sequencing technology}

\author{
Kazuhiro IKEDA ${ }^{1}$, Kuniko HORIE-INOUE ${ }^{1}$, Satoshi INOUE ${ }^{1,2, *}$ \\ ${ }^{1}$ Division of Gene Regulation and Signal Transduction, Research Center for Genomic Medicine, Saitama Medical University, Saitama \\ 350-1241, Japan; '²Department of Anti-Aging Medicine, Graduate School of Medicine, The University of Tokyo, Tokyo 113-8655, \\ Japan
}

\begin{abstract}
Estrogens are important endocrine hormones that control physiological functions in reproductive organs, and play a pivotal role in the generation and progression of breast cancer. Therapeutic drugs including anti-estrogen and aromatase inhibitors are used to treat patients with breast cancer. The estrogen receptors, ER $\alpha$ and ER , function as hormone-dependent transcription factors that directly regulate the expression of their target genes. Therefore, a better understanding of the function and regulation of estrogen-responsive genes provides insight into the gene regulation network associated with breast cancer. Recent technological developments in highthroughput sequencing have enabled the genome-wide identification of estrogen-responsive genes. Further elucidating the estrogen gene cascade is critical for advancements in the diagnosis and treatment of breast cancer.
\end{abstract}

Keywords: steroid hormone; estrogen; nuclear receptor; gene transcription; breast cancer; high-throughput sequencing technique

Acta Pharmacologica Sinica (2015) 36: 24-31; doi: 10.1038/aps.2014.123; published online 15 Dec 2014

\section{Introduction}

The endocrine system produces hormones that have important roles in the development and function of various tissues. Particularly, steroid hormones exert functions through their cognate receptors that act as hormone-dependent transcription factors. Estrogen, glucocorticoid, mineralocorticoid, progesterone, and androgen bind to the estrogen receptor (ER), glucocorticoid receptor (GR), mineralocorticoid receptor (MR), progesterone receptor (PR), and androgen receptor (AR), respectively ${ }^{[1,2]}$. Physiological functions of these steroid hormones are mediated through transcriptional regulation of the target genes ${ }^{[3]}$. Steroid hormone receptor-related transcription networks also contribute to various pathological states, such as cancer, osteoporosis, and inflammation ${ }^{[4]}$. Importantly, estrogen is considered to be involved in the generation and promotion of breast cancer through estrogen signaling. After the hormone binds to its receptors in a cell, it turns on hormone-responsive genes that promote DNA synthesis and cell proliferation $^{[5]}$. Therefore, elucidating the function and regulation of estrogen-regulated genes would uncover the patho-

\footnotetext{
* To whom correspondence should be addressed. E-mail INOUE-GER@h.u-tokyo.ac.jp

Received 2014-07-27 Accepted 2014-10-27
}

physiology of breast cancer ${ }^{[6]}$. In this review, we will discuss recent insights into the role of ER signaling in breast cancer development, which is shown by data from deep-sequencing techniques, including RNA-sequencing (RNA-seq) as well as the genome-wide chromatin immunoprecipitation (ChIP) profiling analyses.

\section{Steroid hormone receptors}

Nuclear receptors have common structural characteristics, ie, they contain N-terminal domain (A/B domain), DNA-binding domain (C domain), hinge domain (D domain), and the C-terminal domain or ligand-binding domain (E/F domain). The activation function 1 (AF-1) in the N-terminal domain has ligand-independent and constitutive transcriptional activity, while the ligand-binding domain contains ligand-dependent transcriptional activity $(\mathrm{AF}-2)^{[7,8]}$. When steroid hormone receptors are not bound by their ligands, their transcriptional activity is inert due to their association with heat shock proteins. When binding to ligands, receptors will dissociate from the heat shock proteins and change their tertiary structure upon dimer formation, phosphorylation, and nuclear localization $^{[9,10]}$. Then, the receptors will bind to hormone response elements (HREs) existing in the transcriptional regulatory regions of their target genes ${ }^{[11]}$. The prototypic estrogen 
response element (ERE) comprises a palindromic consensus sequence of AGGTCA motifs separated by a 3-base spacer. In the case of the androgen-response element (ARE), the palindromic consensus sequence of AGAACA motifs are separated by a 3-base spacer. Interestingly, $A R, P R, G R$, and $M R$ recognize essentially the same consensus sequence. Ligand-bound nuclear receptors associate with transcriptional coactivators and, subsequently, recruit RNA polymerase and general transcription factors (Figure 1) ${ }^{[12]}$.

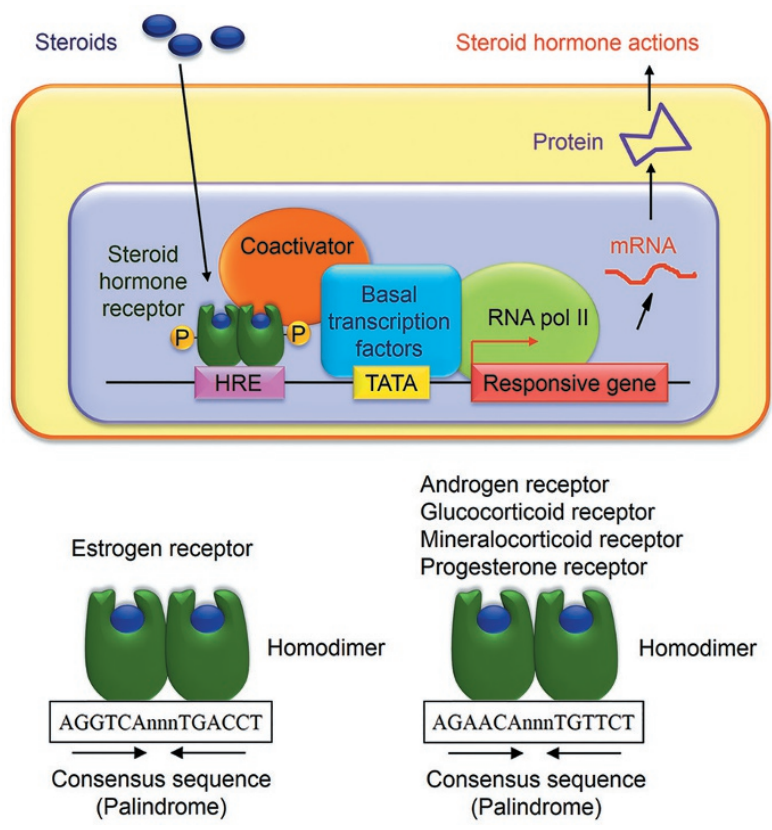

Figure 1. Transcriptional regulation mechanism of steroid hormone receptors. Binding of steroid hormone receptors to the hormone responsive element (HRE) is shown in the lower panel.

The coactivator comprises a protein complex that includes factors possessing histone acetylase or chromatin remodeling activity, which will loosen the chromatin structure and promote the recruitment of the transcription apparatus ${ }^{[13]}$. When the receptor is occupied with an antagonist or free from ligands, it is associated with a transcriptional corepressor that represses transcription ${ }^{[14]}$. Corepressors form a protein complex with histone deacetylases and exert their function to maintain a rigid histone structure. Both coactivators and corepressors are necessary for the effective control of transcription of the target gene. In addition, the nuclear receptor can regulate the transcription of target genes without binding to HREs, $i e$, the nuclear receptor is known to associate with other transcription factors such as Sp1 and AP-1 and then transactivate genes through the binding factors ${ }^{[15,16]}$. Recently, it was shown that FOX family transcription factors influence ERa-regulated transcription by interaction with ERa protein, as exemplified by FOXA1 ${ }^{[17]}$. Genome-wide studies aimed at identifying ERa and AR binding sites (ARBSs) have shown that FOXA1 plays a important role in regulating the networks of both of these nuclear receptors ${ }^{[18,19]}$. FOXA1 is recognized as a pioneer transcription factor because chromatin binding by this protein can enable subsequent recruitment of ERs and ARs to the genome $^{[19,20]}$.

\section{Hormone-dependent cancer and endocrine therapy}

Breast cancer is one of the representative hormone-dependent cancers. Approximately two-thirds of breast cancers express the ER, which plays a critical role in the growth of estrogendependent breast cancer cells ${ }^{[21]}$. The expression of ER relates to various histological characteristics of breast cancer. In general, low-grade breast cancers are usually ER-positive, whereas high-grade cancers are more commonly ER-negative ${ }^{[22]}$ ERpositive tumors usually have a better prognosis than ERnegative tumors. Recently, classification of breast cancer subtypes based on HER2 expression as well as ER and PR status was performed to determine the appropriate treatment and to predict the patient's prognosis ${ }^{[23]}$. In addition, it was shown that the expression patterns of several genes clinically correlate with the outcome of adjuvant therapy and the prognosis of breast cancer patients ${ }^{[24]}$. Thus, gene expression profiling will provide a new taxonomy of breast cancer. In the clinical setting, anti-estrogens and aromatase inhibitors are used in endocrine therapy to treat breast cancer. It was shown that tamoxifen binds to ER and represses its transcriptional activity in breast cancer cells. Aromatase inhibitors appear to decrease the estrogen level in breast cancer cells. Acquired resistance to tamoxifen and aromatase inhibitors, however, is a critical problem in the management of breast cancer, because the majority of patients with breast cancer are treated with these drugs $^{[25]}$. Therefore, elucidation of the mechanisms underlying the estrogen-signaling network in breast cancer will provide useful information to predict the efficacy of endocrine therapy and the prognosis of cancer patients. In addition, functional analysis of estrogen-responsive genes in terms of growth, invasion, and metastasis in breast cancer cells will be useful for the development of new methods for the diagnosis and treatment of the disease.

\section{Steroid hormone target genes and the transcription cascade}

In the 1990s, identification of target genes of steroid hormone receptors was performed using DNA fragments binding to the receptors. In order to isolate estrogen-responsive genes, including EREs in their transcription regulatory regions, we have developed a technique called genomic binding-site cloning $^{[26]}$. Using this method, several genomic sequences containing EREs were successfully isolated and, subsequently, novel estrogen-responsive genes were identified nearby functional EREs ${ }^{[27,28]}$. Protein products of these genes include estrogenresponsive finger protein (Efp), cytochrome $c$ oxidase subunit VIIa-related polypeptide (COX7RP), and estrogen receptorbinding fragment-associated antigen 9 (EBAG9). Abundant expression of Efp is often observed in breast tumors ${ }^{[29]}$, and Efp is an estrogen-inducible gene in MCF7 breast cancer cells. Efp possesses a RING finger motif ${ }^{[29]}$ and functions as 
an ubiquitin ligase E3 for a negative cell cycle regulator 14-3$3 \sigma$ protein, resulting in cell cycle progression via proteasome-

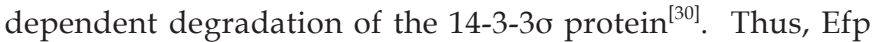
could function as an estrogen-responsive gene that stimulates the proliferation of breast cancer cells. Downregulation of Efp expression by small interfering RNA (siRNA) reagents will be useful for the management of breast cancer, as shown in mouse tumorigenesis models (Figure 2).

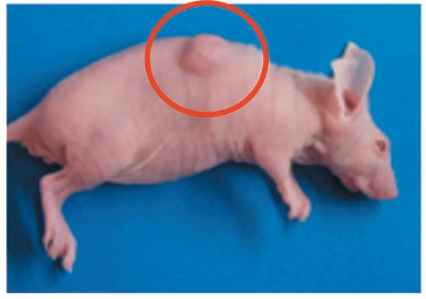

Chimeric siControl



Chimeric siEfp
Figure 2. DNA-modified small interfering RNA (siRNA) against Efp effectively reduces the growth of a tumor derived from MCF-7 breast cancer cells injected in nude mice.

We have recently shown that FOXA1 and FOXP1 expression are estrogen-inducible and they promote the proliferation and/or migration of breast cancer cells by enhancing EREmediated transcription (Figure 3A). Genome-wide chromatin immunoprecipitation (ChIP) analysis on a DNA tiling array (ChIP-chip) showed the presence of estrogen receptor-binding sites (ERBSs) within the human FOXA1 and FOXP1 gene regions in MCF-7 cells ${ }^{[31]}$. These ERBSs involved in FOXA1 and FOXP1 loci were functional and estrogen-dependent in
MCF-7 cells as confirmed by our conventional ChIP analysis. We further demonstrated that the immunoreactivity of both FOXA1 and FOXP1 (Figure 3B) positively correlated with distant disease-free survival for tamoxifen-treated patients of breast cancer ${ }^{[31]}$. These results suggest that pharmacological modulation of FOXA1 and FOXP1 activities would be clinically useful for preventing and/or treating breast cancer, and that evaluation of the immunoreactivity of both FOXA1 and FOXP1 could predict the therapeutic effect of tamoxifen in breast cancer patients.

In addition to the estrogen-responsive genes identified by our group, many other genes have been found to be estrogenregulated, using techniques such as RT-PCR and Northern and Western blot analyses. However, among them, only a small number have been shown to possess functional EREs within the transcription regulatory region. In mammals, these genes include transcription factors, such as $J U N^{[32]}, \mathrm{FOS}^{[33]}$, $P G R^{[34]}$, and $T P 53^{[35]}$, intracellular signaling molecules, such as $H R A S^{[36]}, B C L 2^{[37]}$, and BRCA1 ${ }^{[38]}$, enzymes, such as CHAT ${ }^{[39]}$, $N Q O 1^{[40]}$, and $C K B^{[41]}$, secreted proteins, such as $L T F^{[42]}$, SCGB1A1 $1^{[43]}, O V G P 1^{[44]}, C 3^{[45]}$, and $A G T^{[46]}$, hormones, such as $L H B^{[47]}, O X T^{[48]}, P R L^{[49]}$, and $A V P^{[50]}$, membrane proteins, such as SNAT2 $2^{[51]}$ and VEGFA ${ }^{[52]}$, the motogen TFF1 $1^{[53]}$, and the protease CTSD ${ }^{[54]}$. These genes are assumed to directly mediate various estrogen actions in normal tissues, as well as in cancer and other diseases. However, these genes appear insufficient to explain the estrogen action in breast cancer. Moreover, most of these genes contain an imperfect consensus palindromic ERE or the half site of ERE ${ }^{[55]}$, suggesting that the sequences of EREs in natural promoters of estrogen-responsive genes are diverse. Therefore, genome-wide comprehensive analysis of ER binding sites and estrogen-responsive genes is required to fully elucidate the estrogen-signaling network in breast cancer.

A

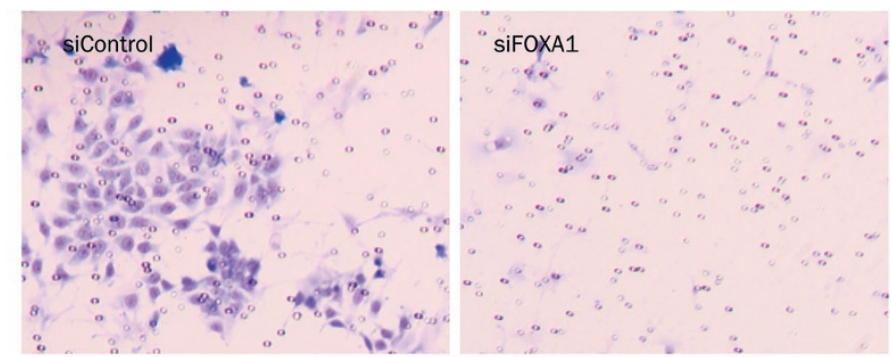

B
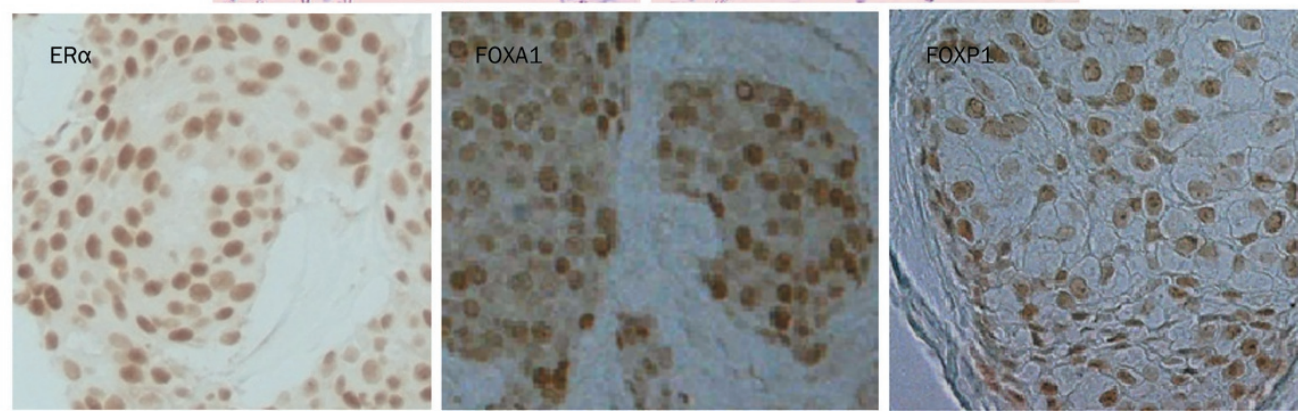

Figure 3. Forkhead transcription factors FOXA1 and FOXP1 contribute to the biology of breast cancer cells. (A) Migration of MCF-7 cells is repressed by small interfering RNA (siRNA)-mediated knockdown of FOXA1. (B) Estrogen receptor (ER) $\alpha$, FOXA1, and FOXP1 immunoreactivities are predominantly observed in the nucleus. 
Identification of estrogen-responsive genes using highthroughput sequencing techniques

Recent advances in high-throughput technologies have further revealed the genome-wide gene regulation mediated by ER. In addition to transcriptome analyses such as RNA-sequencing, CAGE sequencing ${ }^{[56]}$, and microarray analysis, mapping of ER binding sites (ERBSs) is being performed by ChIP-chip or ChIP sequencing (ChIP-seq) analysis, which is a deepsequencing technique for ChIP-derived DNA fragments ${ }^{[57]}$. Integrated studies of transcriptomes and transcription factor binding sites can provide useful information for ER-mediated gene regulation in a genome-wide manner ${ }^{[58]}$. In particular, the development of next-generation sequencing has allowed us to obtain DNA sequence information much more rapidly, and from across the genome. Gene expression microarray studies have been performed to identify the estrogenresponsive genes in breast cancer cells ${ }^{[59-62]}$. However, the effectiveness of expression microarray analysis is decreased by technical issues such as relatively high levels of noise and low sensitivity. In addition, expression microarrays typically do not cover the non-coding RNAs that have been implicated in gene regulation. RNA expression analysis using nextgeneration sequencing (RNA-seq) has resolved these issues, and enables a sensitive and unbiased determination of the estrogen regulation of genes ${ }^{[63,64]}$. In this review, we discuss recent data concerning ERBS and estrogen-responsive genes in breast cancer which have primarily been revealed using highthroughput sequencing technology and ChIP-chip or ChIP-seq technology.

The first comprehensive genome-wide study of ERBSs was performed by Carroll and colleagues using ChIP-chip analysis. Their study identified 3665 ERBSs and 3629 RNA PolII binding sites, and demonstrated that binding of ER at multiple sites is a prerequisite for target gene regulation ${ }^{[59]}$. In addition, the binding motifs of transcription factors, including FOXA1, C/EBP, and Oct, have also shown to be positively correlated with $\mathrm{ER}^{[59]}$. Lin et al used ChIP-paired end diTag (ChIP-PET) technology and deep-sequencing for mapping ERBSs in the genome of MCF-7 cells ${ }^{[65]}$. In their report, 1234 high-confidence ERa-binding sites (ERBSs) were identified and several transcription factor binding motifs, including Sp1, AP-1, and FOXA1 were found to be enriched with the ERBSs. Welboren et al used ChIP-seq technology to explore ERBS and binding sites for RNA polymerase II in the MCF-7 genome in response to estradiol (E2) and antiestrogen, tamoxifen, or fulvestrant ${ }^{[66]}$. They identified the 10205 E2-regulated ERBSs in MCF-7 cells and showed that tamoxifen and fulvestrant partially decrease the binding of ERa and RNA polymerase II around the E2-upregulated genes ${ }^{[6,67]}$. To examine the role of FOXA1 in ERa binding, Hurtado et al performed ChIPseq analysis of ER binding sites in MCF-7 cells in which FOXA1 was silenced with short interfering RNAs (siRNAs) ${ }^{[68]}$. Silencing of FOXA1 decreased the binding intensity at ERBSs that are in the vicinity of FOXA1 binding sites. In addition, silencing of FOXA1 affected the expression of estrogenresponsive genes. Hurtado et al also showed that FOXA1 is necessary for ERa binding in tamoxifen-regulated gene expression in breast cancer cells and that most ER binding sites overlap between estrogen- and tamoxifen-treated cells, implying that FOXA1 also plays a role in tamoxifenmediated transcriptional regulation of $\mathrm{ERa}^{[68]}$. Moreover, they performed formaldehyde-assisted isolation of regulatory elements coupled with high-throughput sequencing (FAIREseq) to identify nucleosome-free and dense chromatin regions in MCF-7 cells and showed that ERa binds to nucleosomedense regions in combination with FOXA1 ${ }^{[68]}$. In addition to the finding that the binding of FOXA1 to ERE is essential for establishing stable recruitment of ER to EREs ${ }^{[68-72]}$, these observations support the notion that the FOXA1 transcription factor functions as a pioneer factor for ER.

Comparative analysis of ChIP-seq data between ER and other transcription factors, such as ELF5, LRH-1, GATA-3, and TLE1, highlighted several key factors influencing ER-mediated gene transcription in breast cancer cells ${ }^{[73-75]}$. In addition to FOXA1, ChIP-seq analysis of FOXM1 revealed that FOXM1 binds at genomic sites simultaneously with ERa and regulates the transcriptional activity of $\mathrm{ERa}^{[76]}$. Genome-wide analysis of ER and retinoic acid receptor (RAR) binding sites in MCF7 cells also demonstrated that a large portion of ERBSs overlap with RAR receptors, suggesting a correlation between these two groups of nuclear receptors ${ }^{[77,78]}$. ChIP-seq analysis of the coregulatory factors for ER, including the p160 family (SRC1, SRC2, and SRC3) and the histone acetyl transferases, p300 and CBP, were performed in MCF-7 cells and revealed a complex network of coregulatory factor binding. In particular, genes possessing preferential binding sites for SRC3 have predictive value for clinical outcome ${ }^{[79]}$. Moreover, in MCF7 cells, unliganded ERa binding to many sites in the chromatin is considered to be involved in maintenance of hormone-dependent breast cancer cells ${ }^{[80]}$.

ChIP-seq technology has also been adapted to improve its application to clinical biopsy material from breast tumors ${ }^{[81]}$. Ross-Innes et al also explored ER binding sites in primary breast cancer using ChIP-seq analysis and identified differential ER-binding profiles that are correlated with good or poor clinical outcomes, suggesting that ChIP-seq analysis will be useful for providing predictive prognoses in breast cancer $^{[82]}$.

Estrogen-regulated gene transcription in MCF-7 cells has also been monitored using GRO-seq, which is a highthroughput sequencing method adapted from nuclear run-on assays. GRO-seq provides the position and orientation of mRNA transcripts engaged by RNA polymerases. Using GRO-seq analysis, Hah et al revealed that the expression of $\sim 3000$ protein-coding genes is regulated by estrogen in MCF-7 cells $^{[83-85]}$. Combined GRO-seq and ChIP-seq analysis in MCF-7 cells has shown that half of the immediate early estrogenresponsive genes possesses ERBSs in the vicinity $(10 \mathrm{~kb})$ of the transcription start site, although other studies have shown that ERBSs are dispersed throughout the genome ${ }^{[59,65,66,69,83]}$.

Data from our recent RNA-seq studies, combined with genome-wide ERBS data ${ }^{[59]}$, were used to identify novel 
estrogen-responsive genes associated with the biology of breast cancer cells. These studies were conducted in breast cancer MCF-7 cells before and after treatment with $17 \beta$-estradiol $\left(\mathrm{E}_{2}\right)^{[63]}$, and $>1000$ genes were identified as estrogen-responsive genes whose expression was altered by at least 2 -fold over basal levels at any time point after estrogen treatment. These genes include prototypic estrogen-responsive genes such as GREB1 and progesterone receptor (PGR) as well as novel estrogen-responsive genes such as RAB17 (Figure 4). Loss-of-function studies of these estrogen-responsive genes revealed that siRNAs targeting MYC, EIF3A, and CCND1 significantly attenuated the growth of MCF-7 cells, and siRNAs specific for RAB17, TPD52L1, MYC, EIF3A, and CCND1 significantly repressed migration of the cells. Similar to prototypic ERa target genes, such as MYC and CCND1, RAB17, TPD52L1, and EIF3A could be new candidate genes that promote the growth or migration of ERa-positive breast cancer cells. It is noteworthy that $R A B 17$ is a member of the Rab family of small GTPases and has been shown to be upregulated by knockdown of extracellular signal-regulated kinase (ERK) 2, which is involved in the growth, migration, and invasion of cancer cells ${ }^{[86]}$. Thus, RAB17 appears to be correlated with a favorable prognosis for ER-positive breast cancer ${ }^{[87]}$.

\section{Conclusion}

The responsive genes of nuclear receptors are vigorously analyzed in genome-wide studies elucidating the cascade of transcriptional regulation networks (Figure 5). Estrogen functions are exerted through the ER-mediated regulatory networks. In these networks, transcriptional regulatory factors common for these receptors are utilized. Furthermore, the networks are functionally modulated by signal transduction pathways in



Figure 4. Estrogen-dependent upregulation of RAB17 in MCF-7 cells demonstrated by RNA-sequencing.

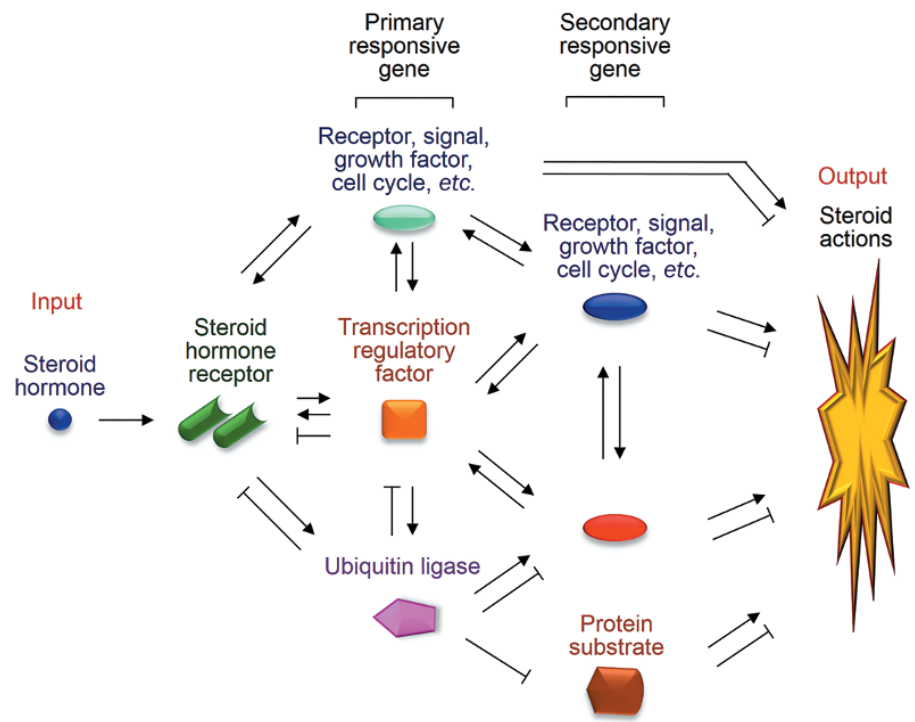

Figure 5. Transcriptional network of steroid hormone receptors and crosstalk with other signals. 
a tissue/cell-specific manner. Genome-wide analysis using high-throughput techniques would be useful for clarifying the transcriptional network. In addition, functional and pathophysiological analyses of each gene involved in the network will reveal the role of the gene in cancer and diseases, which can be applied to the development of new diagnostic and therapeutic devices in clinical medicine.

\section{Acknowledgements}

The authors acknowledge the generous support by Cell Innovation Program, P-DIRECT, and Grants-in-Aid and Support Project of Strategic Research Center in Private Universities from the MEXT, the Program for Promotion of Fundamental Studies in Health Sciences of the NIBIO, grants from the Japan Society for the Promotion of Science and Takeda Science Foundation.

\section{References}

1 Aranda A, Pascual A. Nuclear hormone receptors and gene expression. Physiol Rev 2001; 81: 1269-304.

2 Evans RM. The steroid and thyroid hormone receptor superfamily. Science 1988; 240: 889-95.

3 Muramatsu M, Inoue S. Estrogen receptors: how do they control reproductive and nonreproductive functions? Biochem Biophys Res Commun 2000; 270: 1-10.

4 Sherman MH, Downes M, Evans RM. Nuclear receptors as modulators of the tumor micro environment. Cancer Prev Res (Phila) 2012; 5: 3-10.

5 Platet N, Cathiard AM, Gleizes M, Garcia M. Estrogens and their receptors in breast cancer progression: a dual role in cancer proliferation and invasion. Crit Rev Oncol Hematol 2004; 51: 55-67.

6 Ikeda K, Inoue S. Estrogen receptors and their downstream targets in cancer. Arch Histol Cytol 2004; 67: 435-42.

7 Parker MG. Transcriptional activation by oestrogen receptors. Biochem Soc Symp 1998; 63: 45-50.

8 Arnal JF, Fontaine C, Abot A, Valera MC, Laurell H, Gourdy P, et al. Lessons from the dissection of the activation functions (AF-1 and $A F-2)$ of the estrogen receptor alpha in vivo. Steroids 2013; 78 : 576-82.

9 Hewitt SC, Korach KS. Estrogen receptors: structure, mechanisms and function. Rev Endocr Metab Disord 2002; 3: 193-200.

10 Huang P, Chandra V, Rastinejad F. Structural overview of the nuclear receptor superfamily: insights into physiology and therapeutics. Annu Rev Physiol 2010; 72: 247-72.

11 Umesono K, Evans RM. Determinants of target gene specificity for steroid/thyroid hormone receptors. Cell 1989; 57: 1139-46.

12 Lonard DM, O'Malley BW. Nuclear receptor coregulators: modulators of pathology and therapeutic targets. Nat Rev Endocrinol 2012; 8: 598-604.

13 Dilworth FJ, Chambon P. Nuclear receptors coordinate the activities of chromatin remodeling complexes and coactivators to facilitate initiation of transcription. Oncogene 2001; 20: 3047-54.

14 Dobrzycka KM, Townson SM, Jiang S, Oesterreich S. Estrogen receptor corepressors - a role in human breast cancer? Endocr Relat Cancer 2003; 10: 517-36.

15 Safe S. Transcriptional activation of genes by 17 beta-estradiol through estrogen receptor-Sp1 interactions. Vitam Horm 2001; 62: 231-52.

16 Gustafsson JA. An update on estrogen receptors. Semin Perinatol
2000; 24: 66-9.

17 Carroll JS, Brown M. Estrogen receptor target gene: an evolving concept. Mol Endocrinol 2006; 20: 1707-14.

18 Carroll JS, Liu XS, Brodsky AS, Li W, Meyer CA, Szary AJ, et al. Chromosome-wide mapping of estrogen receptor binding reveals longrange regulation requiring the forkhead protein FoxA1. Cell 2005; 122: 33-43.

19 Lupien M, Eeckhoute J, Meyer CA, Wang Q, Zhang Y, Li W, et al. FoxA1 translates epigenetic signatures into enhancer-driven lineage-specific transcription. Cell 2008; 132: 958-70.

20 Zaret KS, Carroll JS. Pioneer transcription factors: establishing competence for gene expression. Genes Dev 201; 25: 2227-41.

21 Clark GM. Prognostic and predictive factors for breast cancer. Breast Cancer 1995; 2: 79-89.

22 Livasy CA, Karaca G, Nanda R, Tretiakova MS, Olopade OI, Moore DT, et al. Phenotypic evaluation of the basal-like subtype of invasive breast carcinoma. Mod Pathol 2006; 19: 264-71.

23 Olivotto IA, Bajdik CD, Ravdin PM, Speers CH, Coldman AJ, Norris BD, et al. Population-based validation of the prognostic model ADJUVANT for early breast cancer. J Clin Oncol 2005; 23: 2716-25.

24 Carlson JJ, Roth JA. The impact of the Oncotype Dx breast cancer assay in clinical practice: a systematic review and meta-analysis. Breast Cancer Res Treat 2013; 141: 13-22.

25 Michaud LB. Adjuvant use of aromatase inhibitors in postmenopausal women with breast cancer. Am J Health Syst Pharm 2005; 62: 26673.

26 Inoue S, Kondo S, Hashimoto M, Kondo T, Muramatsu M. Isolation of estrogen receptor-binding sites in human genomic DNA. Nucleic Acids Res 1991; 19: 4091-6.

27 Inoue S, Orimo A, Hosoi T, Kondo S, Toyoshima H, Kondo T, et al. Genomic binding-site cloning reveals an estrogen-responsive gene that encodes a RING finger protein. Proc Natl Acad Sci U S A 1993; 90: 11117-21.

28 Watanabe T, Inoue S, Hiroi H, Orimo A, Kawashima H, Muramatsu M. Isolation of estrogen-responsive genes with a $\mathrm{CpG}$ island library. Mol Cell Biol 1998; 18: 442-9.

29 Ikeda K, Orimo A, Higashi Y, Muramatsu M, Inoue S. Efp as a primary estrogen-responsive gene in human breast cancer. FEBS Lett 2000; 472: 9-13.

30 Urano T, Saito T, Tsukui T, Fujita M, Hosoi T, Muramatsu M, et al. Efp targets 14-3-3 $\sigma$ for proteolysis and promotes breast tumour growth. Nature 2002; 417: 871-5.

31 ljichi N, Shigekawa T, Ikeda K, Horie-Inoue K, Shimizu C, Saji S, et al. Association of double-positive FOXA1 and FOXP1 immunoreactivities with favorable prognosis of tamoxifen-treated breast cancer patients. Horm Cancer 2012; 3: 147-59.

32 Hyder SM, Stancel GM, Nawaz Z, McDonnell DP, Loose-Mitchell DS. Identification of an estrogen response element in the $3^{\prime}$-flanking region of the murine c-fos protooncogene. J Biol Chem 1992; 267: 18047-54.

33 Hyder SM, Stancel GM, Loose-Mitchell DS. Presence of an estradiol response region in the mouse c-fos oncogene. Steroids 1991; 56: 498-504.

34 Kastner P, Krust A, Turcotte B, Stropp U, Tora L, Gronemeyer H, et al Two distinct estrogen-regulated promoters generate transcripts encoding the two functionally different human progesterone receptor forms A and B. EMBO J 1990; 9: 1603-14.

35 Berger CE, Qian Y, Liu G, Chen H, Chen X. p53, a target of estrogen receptor (ER) $\alpha$, modulates DNA damage-induced growth suppression in ER-positive breast cancer cells. J Biol Chem 2012; 287: 30117-27. 36 Pethe V, Shekhar PV. Estrogen inducibility of c-Ha-ras transcription in 
breast cancer cells. Identification of functional estrogen-responsive transcriptional regulatory elements in exon 1/intron 1 of the c-Ha-ras gene. J Biol Chem 1999; 274: 30969-78.

37 Perillo B, Sasso A, Abbondanza C, Palumbo G. 17ß-estradiol inhibits apoptosis in MCF-7 cells, inducing bcl-2 expression via two estrogenresponsive elements present in the coding sequence. Mol Cell Biol 2000; 20: 2890-01.

$38 \mathrm{Xu}$ CF, Chambers JA, Solomon E. Complex regulation of the BRCA1 gene. J Biol Chem 1997; 272: 20994-97.

39 Hyder SM, Chiappetta C, Stancel GM. Interaction of human estrogen receptors alpha and beta with the same naturally occurring estrogen response elements. Biochem Pharmacol 1999; 57: 597-601.

40 Montano MM, Jaiswal AK, Katzenellenbogen BS. Transcriptional regulation of the human quinone reductase gene by antiestrogenliganded estrogen receptor-alpha and estrogen receptor-beta. J Biol Chem 1998; 273: 25443-9.

41 Wu-Peng SX, Pugliese TE, Dickerman HW, Pentecost BT. Delineation of sites mediating estrogen regulation of the rat creatine kinase $B$ gene. Mol Endocrinol 1992; 6: 231-40.

42 Zhang Z, Teng CT. Estrogen receptor-related receptor alpha 1 interacts with coactivator and constitutively activates the estrogen response elements of the human lactoferrin gene. J Biol Chem 2000; 275: 20837-46.

43 Slater EP, Redeuihl G, Theis K, Suske G, Beato M. The uteroglobin promoter contains a noncanonical estrogen responsive element. Mol Endocrinol 1990; 4: 604-10.

44 Hyder SM, Stancel GM, Nawaz Z, McDonnell DP, Loose-Mitchell DS. Identification of an estrogen response element in the $3^{\prime}$-flanking region of the murine c-fos protooncogene. J Biol Chem 1992; 267 : 18047-54.

45 Fan JD, Wagner BL, McDonnell DP. Identification of the sequences within the human complement 3 promoter required for estrogen responsiveness provides insight into the mechanism of tamoxifen mixed agonist activity. Mol Endocrinol 1999; 10: 1605-16.

46 Zhao YY, Zhou J, Narayanan CS, Cui Y, Kumar A. Role of C/A polymorphism at -20 on the expression of human angiotensinogen gene. Hypertension 1999; 33: 108-15.

47 Shupnik MA, Weinmann CM, Notides AC, Chin WW. An upstream region of the rat luteinizing hormone beta gene binds estrogen receptor and confers estrogen responsiveness. J Biol Chem 1989; 264: 80-6.

48 Burbach JP, Lopes da Silva S, Cox JJ, Adan RA, Cooney AJ, Tsai MJ, et al. Repression of estrogen-dependent stimulation of the oxytocin gene by chicken ovalbumin upstream promoter transcription factor I. J Biol Chem 1994; 269: 15046-53.

49 Murdoch FE, Byrne LM, Ariazi EA, Furlow JD, Meier DA, Gorski J. Estrogen receptor binding to DNA: affinity for nonpalindromic elements from the rat prolactin gene. Biochemistry 1995; 34: 9144-50.

50 Shapiro RA, Xu C, Dorsa DM. Differential transcriptional regulation of rat vasopressin gene expression by estrogen receptor alpha and beta. Endocrinology 2000; 141: 4056-64.

51 Velázquez-Villegas LA, Ortíz V, Ström A, Torres N, Engler DA, Matsunami R, et al. Transcriptional regulation of the sodium-coupled neutral amino acid transporter (SNAT2) by $17 \beta$-estradiol. Proc Natl Acad Sci U S A 2014; 111: 11443-8.

52 Mueller MD, Vigne JL, Minchenko A, Lebovic DI, Leitman DC, Taylor RN. Regulation of vascular endothelial growth factor (VEGF) gene transcription by estrogen receptors alpha and beta. Proc Natl Acad Sci U S A 2000; 97: 10972-7.

53 Berry M, Nunez AM, Chambon P. Estrogen responsive element of the human pS2 gene is an imperfectly palindromic sequence. Proc Natl
Acad Sci U S A 1989; 86: 1218-22.

54 Augereau P, Miralles F, Cavailles V, Gaudelet C, Parker M, Rochefort $\mathrm{H}$. Characterization of the proximal estrogen-responsive element of human cathepsin D gene. Mol Endocrinol 1994; 8, 693-703.

55 Klinge CM, Estrogen receptor interaction with estrogen response elements. Nucleic Acids Res 2001; 29: 2905-19.

56 Yamaga R, Ikeda K, Boele J, Horie-Inoue K, Takayama K, Urano T, et al. Systemic identification of estrogen-regulated genes in breast cancer cells through cap analysis of gene expression mapping. Biochem Biophys Res Commun 2014; 447: 531-6.

57 Cheung E, Kraus WL. Genomic analyses of hormone signaling and gene regulation. Annu Rev Physiol 2010; 72: 191-218.

58 Vinckevicius A, Chakravarti D. Chromatin immunoprecipitation: advancing analysis of nuclear hormone signaling. J Mol Endocrinol 2012; 49: R113-23.

59 Carroll JS, Meyer CA, Song J, Li W, Geistlinger TR, Eeckhoute J, et al. Genome-wide analysis of estrogen receptor binding sites. Nat Genet 2006; 38: 1289-97.

60 Lin CY, Ström A, Vega VB, Kong SL, Yeo AL, Thomsen JS, et al. Discovery of estrogen receptor alpha target genes and response elements in breast tumor cells. Genome Biol 2004; 5: R66.

61 Cheung E, Kraus WL. Genomic analyses of hormone signaling and gene regulation. Annu Rev Physiol 2010; 72: 191-218.

62 Kininis M, Kraus WL. A global view of transcriptional regulation by nuclear receptors: gene expression, factor localization, and DNA sequence analysis. Nucl Recept Signal 2008; 6: e005.

63 Yamaga R, Ikeda K, Horie-Inoue K, Ouchi Y, Suzuki Y, Inoue S. RNA sequencing of MCF-7 breast cancer cells identifies novel estrogenresponsive genes with functional estrogen receptor-binding sites in the vicinity of their transcription start sites. Horm Cancer 2013; 4: 222-32.

64 Hah N, Kraus WL. Hormone-regulated transcriptomes: lessons learned from estrogen signaling pathways in breast cancer cells. Mol Cell Endocrinol 2014; 382: 652-64.

65 Lin CY, Vega VB, Thomsen JS, Zhang T, Kong SL, Xie M, et al. Wholegenome cartography of estrogen receptor alpha binding sites. PLoS Genet 2007; 3: e87.

66 Welboren WJ, van Driel MA, Janssen-Megens EM, van Heeringen SJ, Sweep FC, Span PN, et al. ChIP-Seq of ERalpha and RNA polymerase II defines genes differentially responding to ligands. EMBO J 2009; 28: $1418-28$.

67 Welboren WJ, Sweep FC, Span PN, Stunnenberg HG. Genomic actions of estrogen receptor alpha: what are the targets and how are they regulated? Endocr Relat Cancer 2009; 16: 1073-89.

68 Hurtado A, Holmes KA, Ross-Innes CS, Schmidt D, Carroll JS. FOXA1 is a key determinant of estrogen receptor function and endocrine response. Nat Genet 2011; 43: 27-33.

69 Carroll JS, Liu XS, Brodsky AS, Li W, Meyer CA, Szary AJ, et al. Chromosome-wide mapping of estrogen receptor binding reveals longrange regulation requiring the forkhead protein FoxA1. Cell 2005; 122: 33-43.

70 Laganière J, Deblois G, Lefebvre C, Bataille AR, Robert F, Giguère V. Location analysis of estrogen receptor alpha target promoters reveals that FOXA1 defines a domain of the estrogen response. Proc Natl Acad Sci U S A 2005; 102: 11651-6.

71 Lupien M, Eeckhoute J, Meyer CA, Wang Q, Zhang Y, Li W, et al. FoxA1 translates epigenetic signatures into enhancer-driven lineage-specific transcription. Cell 2008; 132: 958-70.

72 Zaret KS, Carroll JS. Pioneer transcription factors: establishing competence for gene expression. Genes Dev 2011; 25: 2227-41.

73 Lai CF, Flach KD, Alexi X, Fox SP, Ottaviani S, Thiruchelvam PT, et 
al. Co-regulated gene expression by oestrogen receptor $\alpha$ and liver receptor homolog-1 is a feature of the oestrogen response in breast cancer cells. Nucleic Acids Res 2013; 41: 10228-40.

74 Theodorou V, Stark R, Menon S, Carroll JS. GATA3 acts upstream of FOXA1 in mediating ESR1 binding by shaping enhancer accessibility. Genome Res 2013; 23: 12-22.

75 Holmes KA, Hurtado A, Brown GD, Launchbury R, Ross-Innes CS, Hadfield J, et al. Transducin-like enhancer protein 1 mediates estrogen receptor binding and transcriptional activity in breast cancer cells. Proc Natl Acad Sci U S A 2012; 109: 2748-53.

76 Sanders DA, Ross-Innes CS, Beraldi D, Carroll JS, Balasubramanian S. Genome-wide mapping of FOXM1 binding reveals co-binding with estrogen receptor alpha in breast cancer cells. Genome Biol 2013; 14: R6.

77 Hua S, Kittler R, White KP. Genomic antagonism between retinoic acid and estrogen signaling in breast cancer. Cell 2009; 137: 125971.

78 Ross-Innes CS, Stark R, Holmes KA, Schmidt D, Spyrou C, Russell R, et al. Cooperative interaction between retinoic acid receptor-alpha and estrogen receptor in breast cancer. Genes Dev 2010; 24: 171-82.

79 Zwart W, Theodorou V, Kok M, Canisius S, Linn S, Carroll JS. Oestrogen receptor-co-factor-chromatin specificity in the transcriptional regulation of breast cancer. EMBO J 2011; 30: 4764-76.

80 Caizzi L, Ferrero G, Cutrupi S, Cordero F, Ballaré C, Miano V, et al. Genome-wide activity of unliganded estrogen receptor- $\alpha$ in breast cancer cells. Proc Natl Acad Sci U S A 2014; 111: 4892-7.

81 Zwart W, Koornstra R, Wesseling J, Rutgers E, Linn S, Carroll JS. A carrier-assisted ChIP-seq method for estrogen receptor-chromatin interactions from breast cancer core needle biopsy samples. BMC Genomics 2013; 14: 232.

82 Ross-Innes CS, Stark R, Teschendorff AE, Holmes KA, Ali HR, Dunning $\mathrm{MJ}$, et al. Differential oestrogen receptor binding is associated with clinical outcome in breast cancer. Nature 2012; 481: 389-93.

83 Hah N, Danko CG, Core L, Waterfall JJ, Siepel A, Lis JT, et al. A rapid, extensive, and transient transcriptional response to estrogen signaling in breast cancer cells. Cell 2011; 145: 622-34.

84 Hah N, Murakami S, Nagari A, Danko CG, Kraus WL. Enhancer transcripts mark active estrogen receptor binding sites. Genome Res 2013; 23: 1210-23.

85 Danko CG, Hah N, Luo X, Martins AL, Core L, Lis JT, et al. Signaling pathways differentially affect RNA polymerase II initiation, pausing, and elongation rate in cells. Mol Cell 2013; 50: 212-22.

86 Zacchi P, Stenmark H, Parton RG, Orioli D, Lim F, Giner A, et al. Rab17 regulates membrane trafficking through apical recycling endosomes in polarized epithelial cells. J Cell Biol 1998; 140: 1039-53.

87 von Thun A, Birtwistle M, Kalna G, Grindlay J, Strachan D, Kolch W, et al. ERK2 drives tumour cell migration in three-dimensional microenvironments by suppressing expression of Rab17 and liprin- $\beta 2$. J Cell Sci 2012; 125: 1465-77. 